\title{
Prevalence and associated risk factors of hypertension and pre-hypertension among the adult population: findings from the Dubai Household Survey, 2019
}

\author{
Heba Mamdouh ${ }^{1,2^{*}}$, Wafa K. Alnakhi ${ }^{1,3}$, Hamid Y. Hussain ${ }^{1}$, Gamal M. Ibrahim 1,4, Amal Hussein ${ }^{5}$, \\ Ibrahim Mahmoud ${ }^{5}$, Fatheya Alawadi ${ }^{6}$, Mohamed Hassanein ${ }^{6}$, Mona Abdullatif7, Kadhim AlAbady ${ }^{7}$, \\ Sabya Farooq ${ }^{7}$ and Nabil Sulaiman ${ }^{5,8}$
}

\begin{abstract}
Background: Minimal data is available on the prevalence and correlates of hypertension and prehypertension in Dubai. The study aims to measure the prevalence of hypertension and pre-hypertension and the associated sociodemographic characteristics, behavioral risk factors and comorbidities among the adult population of Dubai.

Methods: This study used data from the Dubai Household Health Survey, 2019. A cross-sectional population survey based on a complex stratified cluster random design. The total eligible sample included 2530 adults (18+). Sociodemographic and behavioral factors were considered as independent covariates. The main study outcome variables, pre-hypertension and hypertension, were ordinal, with normotension as the reference group.

Results: The overall prevalence of hypertension in adults was 32.5\% (38.37\% in males and $16.66 \%$ in females). Prehypertension was prevalent in $29.8 \%$ of adults in Dubai (28.85\% in males and $32.31 \%$ in females). The multivariate logistic regression analysis revealed that age groups, gender, occupation, and high Body Mass Index were significantly associated with a higher risk of hypertension at the level of $P<0.05$. No clear trend toward a higher correlation of hypertension was noted with the increase in age, except after the age of 50 years. Males were five- times more likely to be hypertensive than females. Participants enrolled in skilled and service works had a five times higher risk of hypertension, compared with the reference group (professionals). Obese subjects had a 5.47-times greater correlation of hypertension compared with normal-weight subjects. Physically active individuals were less likely to develop hypertension. For the correlates with prehypertension in the present analysis, skilled and service workers and those working in elementary jobs had a higher risk of prehypertension, compared with the reference group (professionals) Individuals with a status of overweight were associated with a higher prevalence of prehypertension compared with people of normal weight.
\end{abstract}

Conclusions: This study showed a high prevalence of prehypertension and hypertension among adults in Dubai. Some socio-demographic and behavioral risk factors were correlated with prehypertension and hypertension among the studied population. Interventions aiming at increasing public awareness about such risk factors are essential.

\footnotetext{
*Correspondence: hmmohammed@dha.gov.ae

1 Department of Data Analysis, Research and Studies, Dubai Health

Authority, Dubai, UAE

Full list of author information is available at the end of the article
}

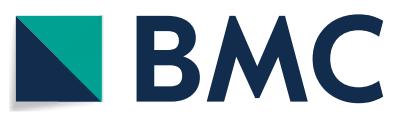

(c) The Author(s) 2022. Open Access This article is licensed under a Creative Commons Attribution 4.0 International License, which permits use, sharing, adaptation, distribution and reproduction in any medium or format, as long as you give appropriate credit to the original author(s) and the source, provide a link to the Creative Commons licence, and indicate if changes were made. The images or other third party material in this article are included in the article's Creative Commons licence, unless indicated otherwise in a credit line to the material. If material is not included in the article's Creative Commons licence and your intended use is not permitted by statutory regulation or exceeds the permitted use, you will need to obtain permission directly from the copyright holder. To view a copy of this licence, visit http://creativecommons.org/licenses/by/4.0/. The Creative Commons Public Domain Dedication waiver (http://creativeco mmons.org/publicdomain/zero/1.0/) applies to the data made available in this article, unless otherwise stated in a credit line to the data. 
Keywords: Hypertension, Pre-hypertension, Dubai population, Socio-demographics, Behavioral risk factors

\section{Introduction}

Hypertension (HTN), defined as elevated blood pressure beyond normal ranges, is recognized as one of the major non-communicable health disorders and a public health challenge worldwide [1]. According to the World Health Organization (WHO), hypertension accounts for one out of eight mortalities worldwide [2]. Hypertension prevalence has risen over the last decades around the world. The latest estimates showed that nearly one-third of the adult world population is having hypertension $(31.1 \%$, 1.39 billion); of whom two-thirds are living in low- and middle-income countries (LMICs) [3]. A systematic analysis of population-based studies from 90 countries estimated that hypertension among adults was more prevalent in LMICs (31.5\%) than in high-income countries (28.5\%) [4]. In particular, the Gulf countries have become one of the most affected in the region with the rising trends of HTN in the world [5]. This is due to the rapid economic development, speedy urbanization, aging of the population, unhealthy dietary habits and lifestyle changes that occurred during the past decades within these countries [6]. Such epidemiological transition significantly contributes to changes in disease patterns and causes a growing number of undiagnosed, diagnosed and uncontrolled hypertensive individuals in many settings [7].

The term prehypertension (PHTN) has been introduced in 2003 to draw attention to the increased risks resulting from high blood pressure [8]. People with PHTN reported having a higher risk of progressing to HTN and an elevated risk of cardiovascular morbidity and mortality $[2,9,10]$. Currently, there is a rising potential for primary prevention and early detection efforts to prevent the transition from PHTN to HTN and the increase in cardiovascular risks [11].

Previous studies have identified several factors that put people at risk of developing HTN $[4,11,12]$. Some are non-modifiable factors such as age, gender, family history, and ethnicity. On the other hand, smoking, alcohol consumption, diet, physical inactivity, Body Mass Index (BMI), abdominal obesity, stress, hyperglycemia, and hypercholesterolemia are among the many modifiable correlates of hypertension [12-15].

Dubai is one of the seven Emirates that make up the United Arab Emirates (UAE) [16]. The Dubai Health Authority (DHA) is the government entity that oversees the health status of the population and ensures excellence in healthcare provision to all residents [17]. Therefore, DHA conducts Dubai Household Surveys (DHHS) on a five-year interval basis to investigate a wide range of health, social and economic issues as well as assessing for PHTN and HTN among the sampled adult population of Dubai.

Studies on the prevalence and correlates of PHTN and HTN among the Dubai population are scarce. Therefore, this study aimed to measure the prevalence of hypertension and pre-hypertension among the adult population of Dubai and to identify the associated sociodemographic characteristics, behavioural risk factors, and comorbidities.

\section{Methodology}

\section{Data source and study design}

This study used data from the 2019 DHHS. The DHHS is a population-based cross-sectional survey that was designed to assess the health status of the population of Dubai. The survey used a multistage stratified cluster sampling technique, based on the WHO World Health Surveys criteria. Clusters were selected based on the simple random method. The clusters were settled as primary sampling units in each stratum, each of which ranged in size from 100 to 200 households. Families were randomly reached by withdrawing a specified number of initial units in each stratum as a first stage, and a specific number of households were withdrawn from each enumeration unit in the second stage. In addition, a number of replacement families were planned to compensate for non-responses. Each participant was assigned a sampling weight, which was inversely proportional to the probability of selection. The proportion of UAE-nationals within the sample was over-sampled, and this was corrected by sample weighting. Out of the total number of adults (18+ years) accepted to participate in the survey, 2530 (include both Emirati and non-Emirati) had their blood pressure measured successfully, which identified the sample size for the current study.

In addition to socio-demographic characteristics and behavioral risk factors data collected through a predesigned questionnaire, participants underwent selected clinical measurements, including blood pressure (BP), anthropometry, and laboratory tests to measure blood sugar levels.

\section{Variables ad measures}

Socio-demographic variables included age, gender, marital status, nationality, education, occupation, and work status. Marital status was categorized as married, single, or others (divorced/ and widowed). Nationality was 
a categorical variable with four groups: UAE-Nationals, Asians, other Arabs, and Western and others. Participant's educational attainment was classified as; 'less than secondary', 'completed secondary or high diploma', and 'university degree or higher education. Participants' occupations were classified based on the international standard classification of occupations and were then re-grouped into three categories; (1) professionals, (2) skilled and service (3) elementary or unskilled occupations, and others [18]. Besides, the socio-demographics, the study also inquired about the health behavior risk factors including smoking, physical activity status and alcohol use. Adequate fruit and/or vegetable consumption was considered if the participant consumed at least five servings/day. Physical activity status was classified as "active" as per the WHO recommendations of at least $30 \mathrm{~min}$ of regular, moderate-intensity physical effort for at least five days a week, totaling $150 \mathrm{~min}$ [19]. Participants were considered as current smokers if they reported smoking any type of tobacco product during the time of the survey. Alcohol consumption was defined as any alcohol usage during the month preceding the survey.

\section{Outcome variables}

HTN and PHTN were operationally defined according to the diagnostic cut-off points of the WHO criteria [8]. Throughout this study, the prevalence of hypertension was based on both self-reported individuals that were previously diagnosed with hypertension and the newly diagnosed during the survey (undiagnosed hypertension). A normal adult has systolic blood pressure (SBP) below $120 \mathrm{mmHg}$ and diastolic blood pressure (DBP) of less than $80 \mathrm{mmHg}$ and was identified as normotensive in the current analysis. Pre-hypertension (recently named as elevated BP) is diagnosed with SPB of $120-139 \mathrm{mmHg}$ or DBP of $80-89 \mathrm{mmHg}$ [20]. While hypertension is defined as SBP of equal to or above $140 \mathrm{mmHg}$ and DBP equal to or above $90 \mathrm{mmHg}$. Participants were screened for hypertension by blood pressure measurements using calibrated sphygmomanometers. Each individual had three blood pressure measurements at two points of time after the first measurement. The mean of the three blood pressure readings was calculated and the participant was labeled as a newly diagnosed hypertensive patient if the definition was met.

Medical conditions included self-reported chronic diseases (referred to as having a chronic condition from a predefined list), having a history of high cholesterol and a history of repeated chest pains. Diabetes status was based on HbA1c test cut-off measures. Participants with HbA1c levels below $6.5 \%$ were considered non-diabetic while those with $\mathrm{HbA1c}$ equal to or above $6.5 \%$ were considered as diabetic, according to the WHO criteria [21]. The overall prevalence of diabetes was based on both the self-reported status and the newly diagnosed diabetes during this survey. BMI was calculated using the formula body weight (in $\mathrm{kg}$ )/ body height (in $\mathrm{m})^{2}$. BMI values below 25 were considered normal, while values between 25 and 29.9 were classified as overweight, and $\mathrm{BMI}$ values of 30 and above indicated obesity as per the WHO Growth Reference [22].

\section{Statistical analysis}

Data coding, data cleaning, and analysis have been carried out by using IBM SPSS (Version 21.0, IBM SPSS, IBM Corp, Armonk, NY, USA) and Stata (Version 15, Stata Corporation, College Station TX). Frequencies and relative frequencies were reported for categorical variables. The Chi-square test of association was used to conduct bivariate analyses and study associations between categorical variables and the outcome variables (hypertension and pre-hypertension). Following the Chi-square test analysis and in order to identify cells with significant findings, post hoc analysis was performed by calculating $P$ values for the adjusted residuals. $P$ values were then compared to the adjusted alpha value using the Bonferroni correction to correct for the inflated type 1 error (data is not provided in the text). Multivariate logistic regression analyses were performed to evaluate significant risk factors for prehypertension (versus normotension) and hypertension (versus normotension). The potential predictors were age, gender, BMI, occupation, smoking status, alcohol consumption and physical activity status. Odds ratios (OR) were reported to reflect the strength of association. All the statistical tests were twosided. The level of significance was set at 5\% $(P<0.05)$ and accordingly, confidence intervals (CIs) were calculated with a $95 \%$ level. Complex weighted computation was used to report the weighted prevalence of HTN and PHTN.

\section{Results}

The total eligible sample included 2530 adults (18+years). Table 1 shows the weighted prevalence of HTN and PHTN according to demographic characteristics. The overall prevalence of HTN was 32.5\% (38.37\% in males and $16.66 \%$ in females). Prehypertension was prevalent in $29.8 \%$ of adults in Dubai $(28.85 \%$ in males and $32.31 \%$ in females). A clear trend toward a greater prevalence of HTN was noted as age increased; however, the prevalence of PHTN was fluctuating among the age groups. Individuals aged $60+$ had the highest proportion of HTN (56.48\%). Moreover, Asians reported the highest frequency of HTN (34.69\%). However, those from western countries and others had the highest frequency of 
Table 1 Prevalence of PHTN and HTN among Dubai population according to socio-demographic characteristics

\begin{tabular}{|c|c|c|c|c|}
\hline \multirow[t]{2}{*}{ Characteristics } & \multicolumn{3}{|l|}{ Prevalence \% } & \multirow[t]{2}{*}{$\wedge P$ value } \\
\hline & Normotensive & PHTN & HTN & \\
\hline \multicolumn{5}{|l|}{ Age group } \\
\hline $18-29$ & 49.13 & 30.98 & 19.89 & \multirow[t]{5}{*}{$<0.001$} \\
\hline $30-39$ & 39.97 & 29.95 & 30.08 & \\
\hline $40-49$ & 33.16 & 28.41 & 38.42 & \\
\hline $50-59$ & 18.20 & 27.90 & 53.90 & \\
\hline $60+$ & 11.25 & 32.27 & 56.48 & \\
\hline \multicolumn{5}{|l|}{ Gender } \\
\hline Females & 51.03 & 32.31 & 16.66 & \multirow[t]{2}{*}{$<0.001$} \\
\hline Males & 32.78 & 28.85 & 38.37 & \\
\hline \multicolumn{5}{|l|}{ Marital status } \\
\hline Single & 48.69 & 30.12 & 21.19 & \multirow[t]{3}{*}{$<0.001$} \\
\hline Married & 33.71 & 29.37 & 36.91 & \\
\hline Divorced/separated/widowed & 21.18 & 38.45 & 40.37 & \\
\hline \multicolumn{5}{|l|}{ Nationality } \\
\hline UAE-Nationals & 42.26 & 32.59 & 25.15 & \multirow[t]{4}{*}{$<0.001$} \\
\hline Other Arabs & 41.98 & 30.98 & 27.03 & \\
\hline Asians & 38.02 & 27.29 & 34.69 & \\
\hline Western and others & 27.93 & 45.05 & 27.02 & \\
\hline \multicolumn{5}{|l|}{ Education level } \\
\hline Less than secondary & 29.92 & 26.02 & 44.06 & \multirow[t]{3}{*}{$<0.001$} \\
\hline Completed secondary and high diploma & 37.16 & 29.45 & 33.40 & \\
\hline Bachelor degree or post-graduates & 42.00 & 31.92 & 26.08 & \\
\hline \multicolumn{5}{|l|}{ Occupation } \\
\hline Professionals & 38.74 & 32.08 & 29.18 & \multirow[t]{3}{*}{$<0.001$} \\
\hline Skilled and service workers & 30.28 & 26.78 & 42.94 & \\
\hline Elementary or unskilled workers & 40.39 & 27.98 & 31.63 & \\
\hline \multicolumn{5}{|l|}{ Work status } \\
\hline Not currently working & 40.52 & 32.92 & 26.57 & \multirow[t]{2}{*}{$<0.001$} \\
\hline Working & 37.19 & 29.22 & 33.59 & \\
\hline \multicolumn{5}{|l|}{ Total prevalence } \\
\hline 37.71 & 29.79 & 32.50 & & \\
\hline
\end{tabular}

Results are presented as weighted proportions for all the categorical variables HTN hypertension, PHTN prehypertension ${ }^{\wedge} \mathrm{X} 2$ test

PHTN (45.05\%) among all other nationalities. Divorced and widowed individuals had a higher prevalence of both PHTN (38.45\%) and HTN (40.37\%) than other marital status categories, $P$ value $<0.001$. Individuals who were currently working had significantly higher (44.06\%) HTN, and among them skilled and service workers had the highest percentage (42.94). Individuals with less than secondary education had higher HTN (44.06\%) than those with bachelor's education and postgraduates. Using the univariate analysis, the prevalence of PHTN and HTN was significantly different within different age groups, gender, nationality groups, marital status, educational attainments, and occupations (all $P$ values $<0.001$ ). Table 2 showed the descriptive univariate analysis for medical conditions associated with PHTN and HTN among the participants. Self-reported histories of certain chronic disorders like high blood cholesterol levels, chest pain, diabetes mellitus (both self-reported and measured), and the measured BMI disorders were all significantly associated with PHTN and HTN, $(P<0.001)$. Hypertensive subjects reported other chronic diseases, high cholesterol levels, and chest pain. Among diabetics in this survey, $61.38 \%$ had HTN, and $55.85 \%$ of obese individuals had HTN. 
Table 2 Medical conditions associated with PHTN and HTN among Dubai population

\begin{tabular}{|c|c|c|c|c|}
\hline \multirow[t]{2}{*}{ Characteristics } & \multicolumn{3}{|l|}{ Prevalence \% } & \multirow[t]{2}{*}{$\wedge P$ value } \\
\hline & Normotension & PHTN & HTN & \\
\hline \multicolumn{5}{|c|}{ Self-reported chronic disease } \\
\hline No chronic diseases & 41.36 & 31.70 & 26.94 & \multirow[t]{2}{*}{$<0.001$} \\
\hline Have chronic diseases & 13.82 & 17.36 & 68.82 & \\
\hline \multicolumn{5}{|c|}{ History of high cholesterol } \\
\hline No cholesterol & 38.61 & 30.46 & 30.93 & \multirow[t]{2}{*}{$<0.001$} \\
\hline Have cholesterol & 32.37 & 25.82 & 41.81 & \\
\hline \multicolumn{5}{|l|}{ Have diabetes $\#$} \\
\hline No diabetes & 42.64 & 32.55 & 24.81 & \multirow[t]{2}{*}{$<0.001$} \\
\hline Have diabetes & 19.20 & 19.42 & 61.38 & \\
\hline \multicolumn{5}{|l|}{ History of chest pain } \\
\hline No & 37.89 & 30.23 & 31.88 & \multirow[t]{2}{*}{$<0.001$} \\
\hline Yes & 32.21 & 16.16 & 51.63 & \\
\hline \multicolumn{5}{|l|}{$B M I$} \\
\hline Normal & 51.18 & 23.90 & 24.92 & \multirow[t]{3}{*}{$<0.001$} \\
\hline Overweight & 37.29 & 25.23 & 37.48 & \\
\hline Obese & 30.43 & 13.75 & 55.82 & \\
\hline
\end{tabular}

\section{BMI: Body Mass Index}

HTN hypertension, PHTN prehypertension

${ }^{\wedge} x^{2}$ test

\# Diabetes here is diagnosed both by tests and the self-reported cases

The associations between behavioral risk factors and PHTN and HTN were shown in Table 3. Using univariate analysis, the current findings reflected that tobacco use, smoking status, passive smoking, eating adequate fruits and vegetable consumption, alcohol consumptions, being physically active, all showed significant statistical associations with the prevalence of PHTN and HTN among the Dubai population at the level of $P<0.001$. Multivariate logistic regression analysis showed that occupations and being overweight were significantly associated with PHTN (compared to normotensive), as shown in Table 4. Age groups and gender were not significantly associated with PHTN. In terms of the current occupation of the participants, skilled and services workers had a higher risk of PHTN, compared to the reference group (professionals) [OR 4.28 (95\% CI 1.80-10.17), OR 2.12 (95\% CI 1.13-4.02), respectively]. Individuals with a status of overweight associated with a higher prevalence of PHTN compared to the normal weighted [OR 2.01 (95\% CI 1.03-3.92)], while obesity was not associated with PHTN. Correlates of HTN as compared to normotensive through multivariable logistic regression analysis were also shown in Table 4. Compared to the reference group (18-29 years), only people aged 50-59 years and those $60+$ years had a greater correlation of developing HTN [OR 3.35 (95\% CI 1.04-10.85), OR 7.59 (95\% CI
Table 3 Behavioral risk factors associated with PHTN and HTN among Dubai population

\begin{tabular}{lcccc}
\hline Characteristics & \multicolumn{2}{c}{ Prevalence \% } & \multirow{2}{*}{${ }^{\wedge} \boldsymbol{P}$ value } \\
\cline { 2 - 3 } & Normotension & PHTN & HTN & \\
\hline Have used tobacco & & & & \\
No & 38.28 & 30.41 & 31.31 & $<0.001$ \\
Yes & 35.40 & 27.31 & 37.29 & \\
Current smoking status & 42.58 & & & \\
No & 34.51 & 15.97 & 41.45 & $<0.001$ \\
Yes & 36.72 & 28.71 & 36.78 & \\
Exposure to passive smoking & & & \\
No & 44.22 & 30.20 & 33.08 & $<0.001$ \\
Yes & 27.06 & 28.72 & \\
Adequate fruits and vegetables consumption & & \\
No & 38.84 & 29.24 & 31.92 & $<0.001$ \\
Yes & 35.31 & 30.94 & 33.75 & \\
Drinking alcohol & & & & \\
No & 38.45 & 30.37 & 31.19 & $<0.001$ \\
Yes & 34.48 & 27.63 & 37.89 & \\
Physically active & & & & \\
No & 37.51 & 29.59 & 32.90 & 0.000 \\
Yes & 13.53 & 31.88 & 54.59 & \\
\hline
\end{tabular}

HTN hypertension, PHTN prehypertension

$\wedge x^{2}$ test

7.13-8.07), respectively]. Males had a higher risk of HTN than females [OR 5.02 (95\% CI 1.61-15.64)]. Similar to PHTN, those who work in skilled and service works had a 4.62 times higher risk of HTN (95\% CI 2.04-10.47), compared to the reference group (professionals). Being overweight carries 2.56 times the risk for HTN compared to normal-weight subjects (95\% CI 1.32-5.00). In addition, obese subjects had a 5.47 times greater correlation of HTN compared to the same reference group (95\% CI 2.57-11.64). Neither smoking nor alcohol drinking was correlated with the risk of developing HTN in the present sample. On the other hand, physically active individuals were less likely to develop HTN [OR 0.51 (95\% CI 0.290.92)], as expected.

\section{Discussion}

\section{Prevalence of PHTN and HTN}

The current findings highlighted a significant burden of both PHTN and HTN in the studied population. The present findings showed that the prevalence of PHTN was $29.8 \%$, which was similar to the figures reported elsewhere [14, 16, 22-24]. However, this result was lower than the figures reported in the neighboring Arabian Gulf countries (37.4\%, 45\%, and 54.9\% in Bahrain, Oman, and Saudi Arabia, respectively) [25-27]. Regarding the prevalence of HTN, the present data also revealed that it 
Table 4 Logistic regression analysis for correlates of PHTN compared to normotensive and HTN compared to normotensive*

\begin{tabular}{|c|c|c|c|c|}
\hline \multirow[t]{2}{*}{ Characteristics } & \multicolumn{2}{|l|}{ PHTN } & \multicolumn{2}{|l|}{ HTN } \\
\hline & OR $(95 \% \mathrm{Cl})$ & $P$ value & OR $(95 \% \mathrm{Cl})$ & $P$ value \\
\hline \multicolumn{5}{|l|}{ Age group (Years) } \\
\hline $18-29$ & Reference group & & Reference group & \\
\hline $30-39$ & $1.34(0.67-2.72)$ & 0.40 & $2.11(0.98-4.27)$ & 0.30 \\
\hline $40-49$ & $1.28(0.58-2.85)$ & 0.53 & $1.51(0.69-3.35)$ & 0.08 \\
\hline $50-59$ & $2.33(0.68-7.99)$ & 0.17 & $3.35(1.04-10.85)$ & $<0.05$ \\
\hline $60+$ & $2.33(0.34-2.87)$ & 0.34 & $7.59(7.13-8.07)$ & $<0.001$ \\
\hline \multicolumn{5}{|l|}{ Gender } \\
\hline Female & Reference group & & Reference group & \\
\hline Male & $1.72(0.71-4.18)$ & 0.22 & $5.02(1.61-15.64)$ & $<0.001$ \\
\hline \multicolumn{5}{|l|}{ Occupation } \\
\hline Professionals & Reference group & & Reference group & \\
\hline Skilled and service workers & $4.28(1.80-10.17)$ & $<0.001$ & $4.62(2.04-10.47)$ & $<0.001$ \\
\hline Elementary/unskilled workers & $2.12(1.13-4.02)$ & $<0.05$ & $1.27(0.70-2.33)$ & 0.430 \\
\hline \multicolumn{5}{|l|}{$\wedge B M I$} \\
\hline Normal & Reference group & & Reference group & \\
\hline Overweight & $2.01(1.03-3.92)$ & $<0.05$ & $2.56(1.32-5.00)$ & $<0.001$ \\
\hline Obese & $2.06(0.90-4.69)$ & $>0.05$ & $5.47(2.57-11.64)$ & $<0.001$ \\
\hline \multicolumn{5}{|l|}{ Smoking status } \\
\hline No & Reference group & & Reference group & \\
\hline Yes & $1.05(0.45-2.48)$ & 0.89 & $1.07(0.49-2.42)$ & 0.850 \\
\hline \multicolumn{5}{|l|}{ Alcohol consumption } \\
\hline No & Reference group & & Reference group & \\
\hline Yes & $0.99(0.53-1.88)$ & 0.99 & $1.71(0.96-3.06)$ & 0.700 \\
\hline \multicolumn{5}{|l|}{ Physically active } \\
\hline No & Reference group & & Reference group & \\
\hline Yes & $0.97(0.55-1.74)$ & 0.93 & $0.51(0.29-0.92)$ & $<0.050$ \\
\hline
\end{tabular}

affects about one-third (32.5\%) of adults in Dubai. This is comparable to the results from other countries worldwide [12, 28-30]. Our prevalence lies within the range of HTN reported in the Gulf States (26.1\%, 34\%, and 37\% in Saudi Arabia, Oman, and Kuwait, respectively) [26, 31, 32]. The differences observed in the prevalence between the Dubai population and other studies with respect to PHTN and HTN could be attributed to dietary and lifestyle factors, cultural and social differences, and the adopted research methodologies. It is worth mentioning that, the proportion of adults with HTN in Dubai was higher than the national average for the UAE of $28.8 \%$ [33]. This might be due to the unique demographics and different dynamics of the population of Dubai, compared to the other Emirates [34].

\section{Risk factors associated with PHTN and HTN}

In the current survey, the logistic regression analysis showed that age, gender, occupation, and BMI were significantly associated with the risk of having HTN. However, physical activity was shown as a protective factor. At the same time, occupation and BMI were the only associated factors with PHTN. The current findings showed that advanced age was associated with an increased risk of HTN. Almost all the studies carried out in different populations had shown a somehow consistent increase in BP with aging [22-29]. Vascular abnormalities might contribute to the high prevalence of HTN in the elderly [35].

Data from the survey revealed a huge gender gap in HTN prevalence between males and females in Dubai. Males were found to be five times more likely to be hypertensive than females. Other studies have confirmed these findings [22-27, 32]. The gender 
differences in hypertension are mainly due to biological factors including sex hormones that keep lower levels of HTN in women, among other factors [36-38]. Behavioral risk factors, including high BMI, smoking, alcohol consumption, and physical inactivity, differ in complex ways between males and females as they play some protective effects in women [28, 36-38]. In addition, women utilize healthcare services more frequently which could have a positive effect on controlling diseases like HTN $[29,36]$.

The present study showed that being overweight was associated with both PHTN and HTN. However, obesity was proven only as a risk factor for HTN within our population. This can be explained by the fact that obese individuals could progress quickly to the actual HTN from the PHTN status [39]. It is worth noting that, $62.1 \%$ of adults in Dubai are either overweight or obese $(41.3 \%$, $20.8 \%$, respectively) [17]. International studies revealed a direct association between increased BMI and HBP and identified obesity as a major risk factor for HTN and PHTN [25-30]. The mechanisms by which obesity contributes to the development of HTN including insulin resistance among other pathophysiological changes [40, 41].

Compared to professionals, skilled and service workers endured a higher risk for both PHTN and HTN within the current population. The influence of occupation as a predictor for high BP has rarely been stated in other studies $[28,32,42]$. Given that there are some variations in the definitions of the occupational categories among different studies, contradictory findings have been reported regarding this association [14, 43]. Similar to the present results, service occupations had a significantly increased prevalence of HTN [44, 45]. However, other studies found that unskilled workers were found to have more HTN than professionals and managerial ones $[45,46]$. The difference in job strains, work environment, and levels of decision-making are among the factors that underlie the differences in HTN prevalence by occupations [47].

In the current study, physical activity was significantly inversely associated with the risk of developing HTN. Consistent evidence from research has endorsed the favorable effects of exercise and physical activities on the control of BP and prevention of HTN $[14,15,48,49]$. Still, there are many unaddressed questions in the nature of the association between physical activity and prevention of HTN in terms of the types, levels and duration of physical activity needed, particularly in high-risk individuals [48].

Unexpectedly, the current findings showed that smoking and alcohol drinking was not associated with PHTN and HTN within the population of Dubai. Our results were not in agreement with other studies [14, 27, 50], since some existing evidence shows that smoking and alcohol drinking were among the risk factors for high BP. The discrepancy between our results and other studies might be explained by the existence of a social stigma attached to smoking and alcohol drinking, especially among females in the Arab region. Therefore, smoking and alcohol drinking could be underreported among the Dubai population [51].

This study has few limitations. First, the survey used data derived from both self-reports and physical measurements. The information collected on a self-reported basis is subjected to some form of bias. Subjectivity, underwriting, or misreporting associated with selfreporting cannot be ignored. A second limitation is that the survey did not collect some important variables such as the family history of HTN, salt and dietary intake of the studied population. Finally, as this survey used a cross-sectional design, the cause and effect relationship could not be established. Despite the above limitations, the strength of this study lies in that it is based on a population survey, which allows a representative population sample. In addition, the current study is the first study to shed light on the prevalence of PHTN and HTN and their correlates at the population level in the emirate of Dubai.

\section{Conclusions}

This is the first study to look at PHTN and HTN among adults in Dubai. The current findings demonstrated that both PHTN and HTN are prevalent among Dubai adults. Clearly, males are at higher risk of having HTN than females. Advanced age is identified to be an independent risk factor for both PHTN and HTN. Further findings showed that overweight, obesity, and occupations significantly predicted the odds of HTN. On the other hand, physical activity was a protective factor from HTN. Therefore, to decrease the burden of PHTN and HTN, early lifestyle modifications including reducing behavioral risk factors might be necessary to prevent the conversion from PHTN to HTN. This can be achieved through improvements in the screening measures and the application of community-based screening services for the early detection of PHTN as well as HTN. Developing and applying a screening tool, such as the cardiovascular risk score, at the primary health care level to detect the high-risk population is recommended. Programs directed at raising the awareness of the community towards the prevention strategies and the health implications of HTN and PHTN are necessary. Developing community initiatives/programs such as food labeling, nutrition interventions, and physical activity programs could be considered as good measures towards the control of BP and its associated cardiovascular risk reduction. Multispectral 
stakeholder's engagement in these programs at different levels is essential. Well-designed future studies are needed to assess the direct association between the different occupation styles, dietary patterns, and types and patterns of physical activity, and the BP status.

\section{Abbreviations}

BMI: Body Mass Index; BP: Blood pressure; Cl: Confidence intervals; DHA: Dubai Health Authority; DHHS: The Dubai Household Health Survey; DBP: Diastolic blood pressure; HTN: Hypertension; OR: Odds ratios; PHTN: Prehypertension; SBP: Systolic blood pressure; WHO: World Health Organization.

\section{Acknowledgements}

The research team would like to express their appreciation and gratitude to the team of Dubai Statistics Centre for their significant contribution to the DHHS.

\section{Authors' contributions}

HM designed the study, drafted the manuscript text, and interpreted the results. WA assisted in writing and reviewing the manuscript. $\mathrm{HH}$ assisted in writing and reviewing the manuscript. Gl performed the statistical analysis and prepared the tables. $\mathrm{AH}$ reviewed the statistical analysis and edited the manuscript. IM reviewed the statistical analysis. NS reviewed the manuscript. All authors reviewed the manuscript. $\mathrm{MH}$ consulted in the new suggested analysis by the reviewers. MA and SF were responsible for re-writing the methodology. FA and KA reviewed the manuscript. All authors read and approved the final manuscript.

\section{Funding}

This research paper did not receive any specific grant from funding agencies in the public, commercial or nonprofit sectors.

\section{Availability of data and materials}

The data that support the findings of this study are from the Dubai Health Authority. However, restrictions apply to the availability of these data; thus, these data are not publicly available. Data are available from the corresponding author upon responsible request with permission from the Dubai Health Authority.

\section{Declarations}

\section{Ethics approval and consent to participate}

Ethical standards were applied throughout this study as per Dubai Health Authority guidelines and regulations. Dubai Scientific Research Ethics Committee, Dubai Health Authority, approved this study (DSREC-GL03-2021). All participants provided written informed consent as well as verbal informed consent to take part in the study.

\section{Consent for publication}

Not applicable.

\section{Competing interests}

The authors declare that they have no competing interests.

\section{Author details}

${ }^{1}$ Department of Data Analysis, Research and Studies, Dubai Health Authority, Dubai, UAE. ${ }^{2}$ Department of Family Health, High Institute of Public Health, Alexandria University, Alexandria, Egypt. ${ }^{3}$ Mohammed Bin Rashid University of Medicine and Health Sciences, Dubai, UAE. ${ }^{4}$ Department of Data Analysis, High Institute for Management Sciences, Belqas, Egypt. ${ }^{5}$ Department of Family and Community Medicine and Behavioral Sciences, College of Medicine, University of Sharjah, Sharjah, UAE. ${ }^{6}$ Department of Diabetes and Endocrinology, Dubai Hospital, Dubai Health Authority, Dubai, UAE. ${ }^{7}$ Public Health Protection Department, Dubai Health Authority, Dubai, UAE. ${ }^{8}$ Baker Heart and Diabetes Institute, Melbourne, VIC, Australia.
Received: 9 June 2021 Accepted: 23 November 2021

Published online: 28 January 2022

\section{References}

1. Kearney PM, Whelton M, Reynolds K, Muntner P, Whelton PK, He J. Global burden of hypertension: analysis of worldwide data. Lancet. 2005;365(9455):217-23.

2. Kim SJ, Lee J, Jee SH, Nam CM, Chun K, Park IS, Lee SY. Cardiovascular risk factors for incident hypertension in the prehypertensive population. Epidemiol Health. 2010;32:e2010003.

3. WHO. Fact sheets: hypertension [Internet]. Who.int. 2021. https://www. who.int/news-room/fact-sheets/detail/hypertension. Accessed 10 May 2021.

4. Mills KT, Bundy JD, Kelly TN, Reed JE, Kearney PM, Reynolds K, Chen J, He J. Global disparities of hypertension prevalence and control: a systematic analysis of population-based studies from 90 countries. Circulation. 2016;134(6):441-50

5. Al-Said J. The prevalence of hypertension in Persian Gulf countries and its correlation with demographic and socio-economic factors. J Hypertens. 2005;23(6):1275-7.

6. Musaiger AO, Al-Khalifa F, Al-Mannai M. Obesity, unhealthy dietary habits and sedentary behaviors among university students in Sudan: growing risks for chronic diseases in a poor country. Environ Health Prev Med. 2016;21(4):224-30.

7. Rahman M, Zaman MM, Islam JY, Chowdhury J, Ahsan HN, Rahman R, Hassan M, Hossain Z, Alam B, Yasmin R. Prevalence, treatment patterns, and risk factors of hypertension and pre-hypertension among Bangladeshi adults. J Hum Hypertens. 2018;32(5):334-48.

8. Chobanian AV, Bakris GL, Black HR, Cushman WC, Green LA, Izzo JL Jr, et al. Seventh report of the joint national committee on prevention, detection, evaluation, and treatment of high blood pressure. Hypertens. 2003;42(6):1206-52

9. Vasan RS, Larson MG, Leip EP, Kannel WB, Levy D. Assessment of frequency of progression to hypertension in non-hypertensive participants in the Framingham Heart Study: a cohort study. Lancet. 2001;358:1682-6.

10. Assadi F. Prehypertension: a warning sign of future cardiovascular risk. Int J Prev Med. 2014;5(Suppl 1):S4.

11. World Health Organization. A global brief on hypertension: silent killer, global public health crisis: World Health Day 2013. Geneva: World Health Organization; 2013.

12. Yang G, Ma Y, Wang S, Su Y, Rao W, Fu Y, Yu Y, Kou C. Prevalence and correlates of prehypertension and hypertension among adults in Northeastern China: a cross-sectional study. Int J Environ Res Public Health. 2016;13(1):82

13. Do HT, Geleijnse JM, Le MB, Kok FJ, Feskens EJ. National prevalence and associated risk factors of hypertension and prehypertension among Vietnamese adults. Am J Hypertens. 2015;28(1):89-97.

14. Waters E, Doyle J. Systematic reviews of public health in developing countries are in train. BMJ. 2004;328(7439):585.

15. Ibekwe RU. Modifiable risk factors of hypertension and socio demographic profile in Oghara, Delta state; prevalence and correlates. Ann Med Health Sci Res. 2015;5(1):71-7.

16. The Seven Emirates - The Official Portal of the UAE Government [Internet]. 2021. https://u.ae/en/about-the-uae/the-seven-emirates.Accessed 1 Mar 2021.

17. Dubai Health Authority. Dubai Household Health Survey. 2021. https:// www.dha.gov.ae/Documents/opendata/English_DDHS.pdf.Accessed 1 Mar 2021.

18. International Standard Classification of Occupations [Internet]. Ilo.org. 2012. https://www.ilo.org/wcmsp5/groups/public/-dgreports/-dcomm/publ/documents/publication/wcms_172572.pdf. Accessed 10 May 2021.

19. Physical activity [Internet]. Who.int. 2020. https://www.who.int/newsroom/fact-sheets/detail/physical-activity. Accessed 13 May 2021.

20. Dominiczak AF, Touyz RM. Hypertension editors welcome comments from regional hypertension societies. Hypertension. 2018;71(6):962.

21. Wild S, Roglic G, Green A, Sicree R, King H. Global prevalence of diabetes: estimates for the year 2000 and projections for 2030. Diab care. 2004;27(5):1047-53 
22. World Health Organization (WHO). Obesity: Preventing and Managing Global Epidemic. WHO Technical Report Series 894; World Health Organization: Geneva, Switzerland, 2000. [Internet]. Available from: https:// www.who.int/news-room/fact-sheets/detail/obesity-and-overweight. Accessed 19 Sept 2021.

23. Silva DA, Petroski EL, Peres MA. Prehypertension and hypertension among adults in a metropolitan area in Southern Brazil: Population-based study. Rev Saude Publica. 2012;46:988-98.

24. Hu L, Huang X, You C, Li J, Hong K, Li P, Wu Y, Wu Q, Bao H, Cheng X. Prevalence and risk factors of prehypertension and hypertension in Southern China. PLoS ONE. 2017;12(1):e0170238.

25. Otayn BI, Hassan Z, Khonji A, Khonji F, Al Jasem D, Saleh SM. Prevalence of prehypertension and the near term risk of developing hypertension among Arabian Gulf University medical students in the Kingdom of Bahrain for the year 2011-2012. World J Pharm Res. 2018;7(14):303-19.

26. Al-Maqbali AA, Temple-Smith M, Ferler J, Blackberry I. Prevalence and determinants of pre-hypertension among Omani adults attending non-communicable disease screening program in primary care setting in Sohar city. Oman Med J. 2013;28(5):316.

27. Aldiab A, Shubair MM, Al-Zahrani JM, Aldossari KK, Al-Ghamdi S, Househ M, Razzak HA, El-Metwally A, Jradi H. Prevalence of hypertension and prehypertension and its associated cardioembolic risk factors; a population based cross-sectional study in Alkharj, Saudi Arabia. BMC Public Health. 2018;18(1):1-9.

28. Singh S, Shankar R, Singh GP. Prevalence and associated risk factors of hypertension: a cross-sectional study in urban Varanasi. Int J Hypertens. 2017:2017:1-10.

29. Tabrizi JS, Sadeghi-Bazargani H, Farahbakhsh M, Nikniaz L, Nikniaz Z. Prevalence and associated factors of prehypertension and hypertension in Iranian population: the Lifestyle Promotion Project (LPP). PLOS ONE. 2016;11(10):e0165264

30. Rana J, Oldroyd J, Islam MM, Tarazona-Meza CE, Islam RM. Prevalence of hypertension and controlled hypertension among United States adults: evidence from NHANES 2017-18 Survey. Int J Cardiol Hypertens. 2020:7:100061.

31. Al-Nozha MM, Abdullah M, Arafah MR, Khalil MZ, Khan NB, Al-Mazrou YY, Al-Maatouq MA, Al-Marzouki K, Al-Khadra A, Nouh MS, Al-Harthi SS. Hypertension in Saudi Arabia. Saudi Med J. 2007;28(1):77.

32. Channanath AM, Farran B, Behbehani K, Thanaraj TA. State of diabetes, hypertension, and comorbidity in Kuwait: showcasing the trends as seen in native versus expatriate populations. Diabetes Care. 2013;36(6):e75.

33. UAE NATIONAL HEALTH SURVEY REPORT 2017-2018 [Internet]. Dubai, UAE. 2019. https://www.mohap.gov.ae/Files/MOH_OpenData/1556/UAE_ NHS_2018.pdf. Accessed 14 May 2021.

34. Demographics of Dubai. https://en.wikipedia.org/wiki/Demographics_ of_Dubai. Accessed 1 Mar 2021.

35. Lionakis N, Mendrinos D, Sanidas E, Favatas G, Georgopoulou M. Hypertension in the elderly. World J Cardiol. 2012;4(5):135.

36. Everett B, Zajacova A. Gender differences in hypertension and hypertension awareness among young adults. Biodemography Soc Biol. 2015:61(1):1-7.

37. Sandberg K, Ji H. Sex differences in primary hypertension. Biol Sex Differ. 2012:3(1):1-21.

38. Vitale C, Fini M, Speziale G, Chierchia S. Gender differences in the cardiovascular effects of sex hormones. Fundam Clin Pharmacol. 2010;24(6):675-85.

39. Recio-Rodriguez JI, Gomez-Marcos MA, Patino-Alonso MC, Agudo-Conde C, Rodriguez-Sanchez E, Garcia-Ortiz L. Abdominal obesity vs general obesity for identifying arterial stiffness, subclinical atherosclerosis and wave reflection in healthy, diabetics and hypertensive. BMC CardiovasC Disord. 2012;12(1):1-8

40. Jayedi A, Rashidy-Pour A, Khorshidi M, Shab-Bidar S. Body mass index, abdominal adiposity, weight gain and risk of developing hypertension: a systematic review and dose-response meta-analysis of more than 2.3 million participants. Obes Rev. 2018;19(5):654-67.

41. DeMarco VG, Aroor AR, Sowers JR. The pathophysiology of hypertension in patients with obesity. Nat Rev Endocrinol. 2014;10(6):364.

42. Landsbergis PA, Diez-Roux AV, Fujishiro K, Baron S, Kaufman JD, Meyer JD, Koutsouras G, Shimbo D, Shrager S, Stukovsky KH, Szklo M. Job strain, occupational category, and hypertension prevalence: the Multi-Ethnic Study of Atherosclerosis. Occup Environ Med. 2015;57(11):1178.
43. Gilbert-Ouimet M, Trudel X, Brisson C, Milot A, Vézina M. Adverse effects of psychosocial work factors on blood pressure: systematic review of studies on demand-control-support and effort-reward imbalance models. Scand J Work Environ Health. 2014;1:109-32.

44. Davila EP, Kuklina EV, Valderrama AL, Yoon PW, Rolle I, Nsubuga P. Prevalence, management, and control of hypertension among US workers: does occupation matter? Occup Environ Med. 2012;54(9):1150-6.

45. Colhoun HM, Hemingway H, Poulter NR. Socio-economic status and blood pressure: an overview analysis. J Hum Hypertens. 1998;12(2):91-110.

46. Keenan NL, Rosendorf KA, Centers for Disease Control and Prevention (CDC). Prevalence of hypertension and controlled hypertension-United States, 2005-2008. MMWR Surveill Summ. 2011;60(Suppl):94-7.

47. Babu GR, Jotheeswaran AT, Mahapatra T, Mahapatra S, Kumar A Detels R, Pearce N. Republished: is hypertension associated with job strain? A meta-analysis of observational studies. Occup Environ Med. 2014;71(3):220-7

48. Diaz KM, Shimbo D. Physical activity and the prevention of hypertension. Curr Hypertens Rep. 2013;15(6):659-68.

49. Carey R, Muntner P, Bosworth H, Whelton P. Prevention and control of hypertension: JACC Health Promotion Series. J Am Coll Cardiol. 2018;72(11):1278-93.

50. Rajkumar E, Romate J. Behavioural risk factors, hypertension knowledge, and hypertension in rural India. Int J Hypertens. 2020;2020:1-7.

51. Jarallah JS, Al-Rubeaan KA, AI-Nuaim AR, Al-Ruhaily AA, Kalantan KA. Prevalence and determinants of smoking in three regions of Saudi Arabia. Tob Control. 1999:8(1):53-6.

\section{Publisher's Note}

Springer Nature remains neutral with regard to jurisdictional claims in published maps and institutional affiliations.

Ready to submit your research? Choose BMC and benefit from

- fast, convenient online submission

- thorough peer review by experienced researchers in your field

- rapid publication on acceptance

- support for research data, including large and complex data types

- gold Open Access which fosters wider collaboration and increased citations

- maximum visibility for your research: over $100 \mathrm{M}$ website views per year

At BMC, research is always in progress.

Learn more biomedcentral.com/submissions 